In conclusion, our novel method might effectively reconstruct aortic sinuses and annuluses simultaneously without an additional risk of intraoperative bleeding. However, the number of patients treated with this method is low, and a long-term follow-up with a significant patient cohort is mandatory to confirm its effectiveness.

\section{References}

1. Yacoub MH, Gehle P, Chandrasekaran V, Birks EJ, Child A, Radley-Smith R. Late results of a valve-preserving operation in patients with aneurysms of the ascending aorta and root. J Thorac Cardiovasc Surg. 1998;115:1080-90.

2. David TE, Ivanov J, Armstrong S, Feindel CM, Webb GD. Aortic valve-sparing operations in patients with aneurysms of the aortic root or ascending aorta. Ann Thorac Surg. 2002;74(suppl):S1758-6.

\title{
Right ventricular exclusion procedure for right ventricular failure of Ebstein's anomaly
}

\author{
Sungkyu Cho, MD, ${ }^{\text {a }}$ Woong-Han Kim, MD, PhD, ${ }^{\mathrm{a}}$ Jae Gun Kwak, MD, ${ }^{\mathrm{b}}$ and Chun Su Park, MD, ${ }^{\mathrm{a}}$ \\ Seoul, Korea
}

Ebstein's anomaly is a broad spectrum of disease characterized by varying degrees of downward displacement of the septal and posterior leaflets of the tricuspid valve into the right ventricular cavity and atrialized and dilated changes of the right ventricle. There are various surgical techniques according to the severity of desease. ${ }^{1}$ There are some descriptions about the right ventricular exclusion procedure for progressed congestive right-sided heart failure after primary biventricular repair or neonatal stenotic Ebstein's anomaly. ${ }^{2,3}$ We evaluated the preoperative and postoperative cardiac function and ventricular size by cardiac magnetic resonance imaging after the right ventricular exclusion procedure in Ebstein's anomaly.

\section{CLINICAL SUMMARY}

A 21-year-old woman who was born with Ebstein's anomaly (Carpentier type B-C) underwent tricuspid valve repair and right ventricular volume reduction with the Danielson technique at 5 years of age and tricuspid valve replacement and bidirectional cavopulmonary shunt at 16 years of age. At 21 years of age, she had severe congestive right ventricular failure (New York Heart Association

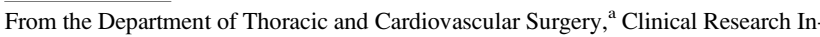
stitute, Seoul National University Children's Hospital, Seoul National University College of Medicine, Seoul, Korea; and Department of Cardiothoracic Surgery, ${ }^{b}$ Sejong General Hospital, Bucheon, Korea.

Received for publication Aug 4, 2008; accepted for publication Sept 11, 2008; available ahead of print Jan 27, 2009.

Address for reprints: Woong-Han Kim, MD, PhD, Department of Thoracic and Cardiovascular Surgery, Seoul National University College of Medicine, Seoul National University Children's Hospital, 28 Yongon-Dong, Jongno-Gu, Seoul, 110-744, Korea (E-mail: woonghan@snu.ac.kr).

J Thorac Cardiovasc Surg 2009;138:1246-8

$0022-5223 / \$ 36.00$

Copyright (C) 2009 by The American Association for Thoracic Surgery doi:10.1016/j.jtcvs.2008.09.029
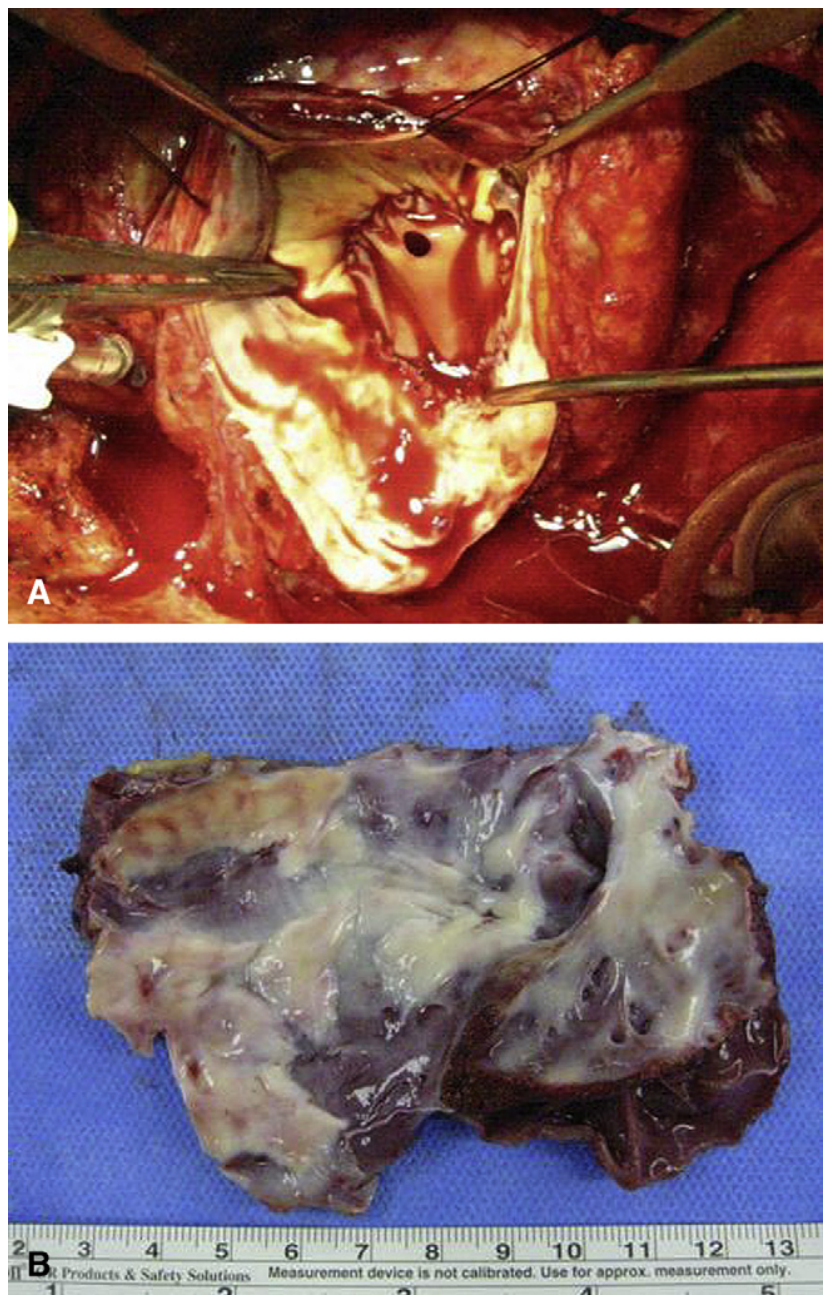

FIGURE 1. A, Previous tricuspid valve orifice was closed with a bovine pericardial patch while creating a $5-\mathrm{mm}$ atrioventricular communication. $\mathrm{B}$, Resected right ventricle. 

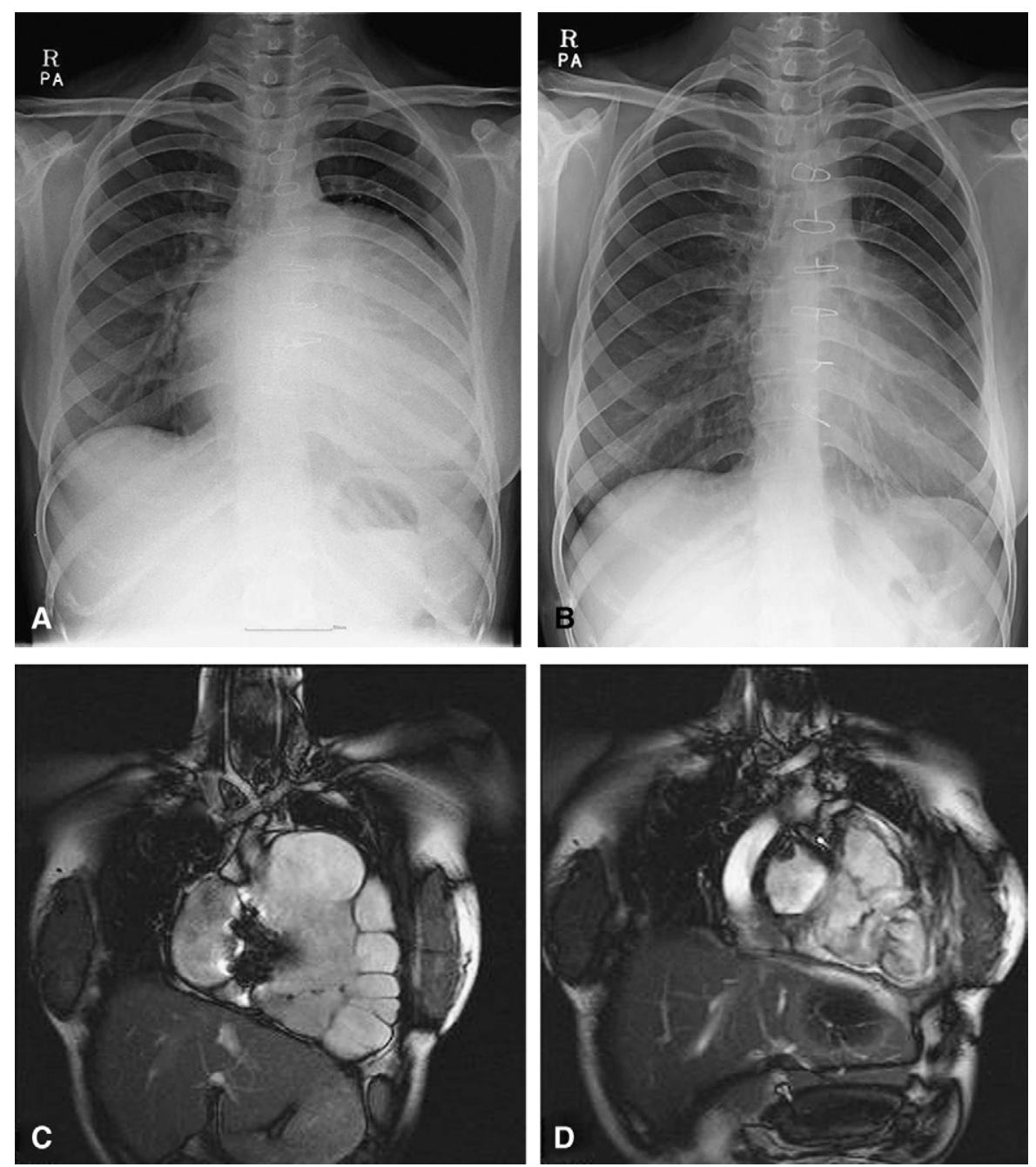

FIGURE 2. Preoperative chest $\mathrm{X}$-ray (A) and cardiac magnetic resonance imaging scan (C) showing severe cardiomegaly with huge right atrium and atrialized and septated right ventricle. Postoperative chest radiograph (B) after 6 months and cardiac magnetic resonance image (D) at discharge show decreased heart size and an obliterated atrialized right ventricle with Fontan flow.

FC-IV), with the highest brain natriuretic peptide value up to $562 \mathrm{pg} / \mathrm{mL}$. Echocardiography showed a dilated and poorly contracting right ventricle, a huge right atrium, paradoxical motion of ventricular septum, a dilated hepatic vein, and a poorly contracting left ventricle. Cardiac magnetic resonance imaging showed hypofunction of the left ventricle. Left ventricular ejection fraction was $14.2 \%$, and left enddiastolic volume was $180.0 \mathrm{~mL}$. Atrial flutter and tachyarrhythmia were observed on electrocardiogram and 24-hour Holter monitoring. After 3 months of medical treatment, the patient underwent the Fontan operation.

Operative findings showed a hugely dilated right atrium and right ventricle with a multiple septated cavity and fibrotic change at the inner wall. Via a midline sternotomy, cardiopulmonary bypass was commenced with bicaval and aortic cannulation. After division of the main pulmonary artery, the pulmonary valve was obliterated. The right atrial free wall was almost resected. The previous tissue valve at the tricuspid valve position was removed, and its orifice was closed with a bovine pericardial patch, which allowed the coronary sinus to drain into the right atrium, while creating a 5-mm atrioventricular communication to drain blood from the right ventricle into the atrium (Figure 1). After a large portion of the right ventricular free wall was excised, the residual cavity of the right ventricle was obliterated with multiple interrupted mattress sutures. A rightsided Maze procedure was also performed with a cryoprobe. The residual right ventricular free wall was closed with bovine pericardial felt-supported suture. A wide atrial septal defect was created, and the right atrium was closed. After aortic declamping, an extracardiac total cavopulmonary connection was constructed with 22-mm expanded polytetrafluoroethylene tube conduit (Gore-Tex vascular graft; WL Gore \& Associates Inc, Flagstaff, Ariz). The patient was extubated on postoperative day 1 and discharged on postoperative day 19. The cardiothoracic ratio decreased 
TABLE 1. Values of preoperative and postoperative echocardiography (postoperative day 4) and cardiac magnetic resonance imaging (postoperative day 12)

\begin{tabular}{llcc}
\hline & & $\begin{array}{c}\text { Preoperative } \\
\text { value }\end{array}$ & $\begin{array}{c}\text { Postoperative } \\
\text { value }\end{array}$ \\
\hline Echocardiography & LVEF $(\%)$ & 20.5 & 47 \\
& LVIDd (mm) & 37.4 & 36 \\
Cardiac MRI & LVEF $(\%)$ & 14.2 & 35.8 \\
& LVEDV (mL) & 121.6 & 87.2 \\
& CO (L/min) & 1.82 & 2.59 \\
& RVEDV (mL) & 528.3 & 146 \\
\hline
\end{tabular}

$L V E F$, Left ventricular ejection fraction; $L V I D d$, left ventricular internal diastolic diameter; $L V E D V$, left ventricular end-diastolic volume; $C O$, cardiac output; $R V E D V$, right ventricular end-diastolic volume; $M R I$, magnetic resonance imaging.

from the $67 \%$ preoperative value to $54 \%$. Postoperative echocardiography revealed no paradoxical motion of the interventricular septum and a left ventricular ejection fraction of $47 \%$. Cardiac magnetic resonance imaging revealed a left ventricular ejection fraction of $35.8 \%$ and left ventricular end-diastolic volume of $124.6 \mathrm{~mL}$ (Figure 2). There was no arrhythmia on 24-hour Holter monitor. Eight months after the operation, the patient was in New York Heart Association functional class I with digoxin and angiotensin-converting inhibitor medication. Measured values by echocardiography and cardiac magnetic resonance imaging are shown in Table 1.

\section{CONCLUSIONS}

In this case, the right ventricular exclusion procedure not only normalized paradoxical interventricular septal motion but also increased effective volume loading of the left ventricle. The postoperative measured ratio $(0.62 \mathrm{~g} / \mathrm{mL})$ of left ventricular mass to left ventricular end-diastolic volume, which was normalized by body surface area, increased more than the preoperative measured ratio $(0.41$ $\mathrm{g} / \mathrm{mL}$ ). As a result, left ventricular ejection fraction improved. The right ventricular exclusion procedure may be effective for repairing arrhythmia by resecting the arrhythmogenic dysplastic and dilated right ventricle. As in this case, the right ventricular exclusion procedure may be a good option for severe congestive right ventricular failure of Ebstein's anomaly.

\section{References}

1. Kumar AE, Flyer DC, Miettinen OS, Nadas AS. Ebstein's anomaly: clinical profile and natural history. Am J Cardiol. 1971;28:84-95.

2. Starnes VA, Pitlick PT, Bernstein D, Griffin ML, Choy M, Shumway NE. Ebstein's anomaly appearing in the neonate: a new surgical approach. J Thorac Cardiovasc Surg. 1991;101:1082-7.

3. Sano S, Ishino K, Kawada M, Kasahara S, Kohmoto T, Takeuchi M, et al. Total right ventricular exclusion procedure: an operation for isolated congestive right ventricular failure. J Thorac Cardiovasc Surg. 2002;123:640-7.

\title{
Use of moldable titanium bars and rib clips for total sternal replacement: A new composite technique
}

\author{
Alessandro Gonfiotti, MD, ${ }^{\mathrm{a}}$ Paolo Ferruccio Santini, MD, ${ }^{\mathrm{a}}$ Domenico Campanacci, MD, ${ }^{\mathrm{b}}$ \\ Marco Innocenti, MD, ${ }^{\mathrm{c}}$ Sante Ferrarello, MD,${ }^{\mathrm{d}}$ and Alberto Janni, MD, ${ }^{\mathrm{a}}$ Florence, Italy
}

After a total sternectomy, a rigid prosthetic replacement is usually recommended to protect the lungs, heart, and main vessels and to prevent paradoxical respiration. ${ }^{1}$ The most common system used for rigid reconstruction of the sternum is methyl methacrylate, which is difficult to handle and mold

From the Thoracic Surgery Unit, ${ }^{\mathrm{a}}$ Orthopedic Oncology, ${ }^{\mathrm{b}}$ Plastic Surgery, ${ }^{\mathrm{c}}$ and Anesthesiology Unit, ${ }^{\mathrm{d}}$ University Hospital Careggi, Florence, Italy.

Received for publication July 14, 2008; revisions received Sept 4, 2008; accepted for publication Sept 14, 2008; available ahead of print Dec 1, 2008.

Address for reprints: Alessandro Gonfiotti, MD, Thoracic Surgery Unit, Azienda Ospedaliero-Universitaria Careggi, Viale Pieraccini n17, 50100, Firenze, Italy

(E-mail: agonfiotti@alice.it).

J Thorac Cardiovasc Surg 2009;138:1248-50

$0022-5223 / \$ 36.00$

Copyright $\odot 2009$ by The American Association for Thoracic Surgery

doi:10.1016/j.jtcvs.2008.09.034 into the correct shape. ${ }^{2}$ We describe a rigid sternal reconstruction after total sternectomy using a new system with moldable titanium bars and rib clips.

\section{CLINICAL SUMMARY}

A 65-year-old woman was admitted to our unit for a large and palpable chondrosarcoma of the sternum. The computed tomogram confirmed a lesion occupying the whole sternal body along with invasion of the manubrium (Figure 1, A), and a positron emission tomogram revealed a strong accumulation in the lesion, without accumulation elsewhere in the body. On this basis we performed a total sternectomy, including the entire sternum together with the previous site of biopsy, costochondral arches, and internal third of clavicles, 